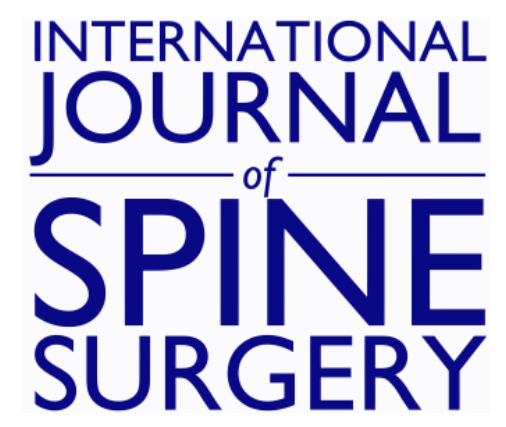

\title{
Minimally invasive surgery for lumbar synovial cysts with coexisting degenerative spondylolisthesis
}

Daniel R. Denis, Daniel Hirt, Saumya Shah, Daniel C. Lu and Langston T. Holly

Int J Spine Surg 2016, 10 ()

doi: https://doi.org/10.14444/3037

http://ijssurgery.com/content/10/37

This information is current as of April 26, 2023.

Email Alerts Receive free email-alerts when new articles cite this article. Sign up at:

http://ijssurgery.com/alerts

The International Journal of Sbinesurgerth 2397 Waterbury Circle, Suite 1,

Aurora, IL 60504, Phone: +1-630-375-1432

(C) 2016 ISASS. All Rights Reserved. 


\section{Minimally invasive surgery for lumbar synovial cysts with coexisting degenerative spondylolisthesis}

Daniel R. Denis, MD, ${ }^{1}$ Daniel Hirt, MD, ${ }^{2}$ Saumya Shah, ${ }^{2}$ Daniel C. Lu, MD, PhD, ${ }^{2}$ Langston T. Holly, MD 2

${ }^{1}$ Department of Neurosurgery, Ochsner Medical Center, New Orleans, LA, USA, 2Department of Neurosurgery, University of California, Los Angeles, CA, USA

\section{Abstract}

Background

About one third of lumbar synovial cysts are associated with degenerative spondylolisthesis. Segmental instability is thought to contribute to the pathogenesis and recurrence of synovial cysts and lumbar fusion has been advocated as a treatment of choice in the presence of spondylolisthesis. In patients with spondylolisthesis, minimally invasive resection of lumbar synovial cysts, without fusion, could minimize surgically induced segmental instability while providing good pain relief.

Methods

Clinical and radiological outcomes of lumbar synovial cyst patients with and without spondylolisthesis were retrospectively compared. Pain outcomes were assessed with modified Macnab criteria.

Results

Fifty-three patients (18 with grade 1 spondylolisthesis) underwent minimally invasive synovial cyst resection and all had either excellent or good pain outcome at $\leq 8$ post- operative weeks $(\mathrm{P}=1.000, \mathrm{n}=53)$. At $>8$ post-operative weeks (mean (SD) follow-up of 200 (175) weeks), excellent or good outcomes were noted in $89 \%$ of patients without spondylolisthesis and in $75 \%$ of patients with spondylolisthesis $(\mathrm{P}=0.425, \mathrm{n}=40)$. Four patients developed a new grade 1 spondylolisthesis at a mean follow-up of $2.6 \pm 2.1$ years. Nine patients were assessed for spondylolisthesis measurements at $1.2 \pm 1.3$ years of follow up and no significant difference was observed ( $5 \pm 0 \mathrm{vs} 5 \pm 1 \mathrm{~mm}$; $\mathrm{P}$ $=0.791$ ). Two patients without spondylolisthesis and none of the patients with spondylolisthesis had a synovial cyst recurrence.

Conclusion

Patients with concomitant lumbar degenerative spondylolisthesis and synovial cyst can have good short- and longterm clinical outcomes with minimally invasive surgery without fusion. Post-operative segmental instability does not appear to be significant in patients with spondylolisthesis.

All patients included in this article signed an informed consent for the use of their medical information for research.

KEYWORDS: MINIMALLY INVASIVE SURGERY, SYNOVIAL CYST, SPONDYLOLISTHESIS, OUTCOMES

VOLUME 10 ARTICLE 37 DOI: 10.14444/3037

\section{Introduction}

Lumbar spinal synovial cysts are a potential cause of radiculopathy, back pain and neurogenic claudication. ${ }^{1-3}$ Lined with synovial cells, these cysts arise from the facet joint and are often associated with spondylosis, traumatic injury or spinal instability. ${ }^{4-7}$

Symptomatic lumbar synovial cysts can be treated by several modalities. Traditional open surgical manage- ment, which consists of laminectomy or hemilaminectomy, medial facetectomy and excision of the cyst generally provides superior outcomes than more conservative approaches such as intraarticular corticosteroid injections or percutaneous cyst aspiration. ${ }^{8-11}$

Segmental instability has been reported to contribute to the pathogenesis and recurrence of synovial cysts, and degenerative spondylolisthesis is thought to be Downloaded from http://ijssurgery.com/ by guest on April 26, 2023 
such a predisposing factor. ${ }^{11,12}$ Due to concerns about progressive instability, laminectomy with lumbar fusion has been advocated as the best treatment option for synovial cysts with spondylolithesis. ${ }^{9}{ }^{13}$ However lumbar fusion procedures involve increased operative time and blood loss as well as the risk of developing adjacent segment disease. ${ }^{14}$

Recent studies using minimally invasive techniques with tubular retractors for decompression and resection of synovial cysts have showed promising results in a limited number of patients. ${ }^{15-18}$ This type of approach decreases damage to surroundings muscular, bony and ligamentous structures and could potentially minimize segmental instability, particularly in the presence of preexisting spondylolisthesis. ${ }^{16,19}$ However there is no published study on minimally invasive resection of lumbar synovial cysts that compares outcomes between patients with and without spondylolisthesis.

In this study, we report our clinical experience with minimally invasive resection of synovial cysts. Clinical data, surgical endpoints and radicular pain outcomes between patients with and without lumbar degenerative spondylolisthesis are compared. Development or progression of spondylolisthesis at the operated level and radiological outcomes of patients with preoperative spondylolisthesis are also examined.

\section{Material and Methods}

Patient Population

Clinical and radiological data of patients from the present authors' institution (LTH and DCL) that underwent a minimally invasive resection of lumbar synovial cyst, between March 2003 to February 2014, were retrospectively collected using our health electronic record software. Indications for minimally invasive surgery were the presence of a lumbar synovial cyst with corresponding radiculopathy. Patients presenting with a lumbar synovial cyst and a concomitant grade 1 degenerative spondylolisthesis were offered the same minimally invasive surgery. Patients with instability on standing flexion-extension radiographs were excluded from the study. All patients received a minimum of 6 weeks of conservative management that included nonsteroidal anti- inflammatory drugs, physical therapy and epidural steroid injections.

\section{Radiographic imaging and operative technique} Synovial cysts location and size were determined with lumbar spinal magnetic resonance imaging (MRI) (Figure 1). Plain standing lateral radiographs were used to identify and measure lumbar spondylolisthesis preoperatively and on follow-ups. Persistent or new radicular pain symptoms on postoperative follow-up visits were investigated with a second lumbar spine MRI. The operative technique for ipsilateral minimally invasive synovial cyst resection using a tubular retractor system was carried out according to Sehati et al. (2006).

Under microscopic visualization, the soft tissue overlying the facet and lamina was resected using monopolar cautery and a hemilaminotomy and medial facetectomy was performed with the high-speed drill. The remaining bone and ligamentum flavum was resected with Kerrison instruments and the synovial cyst was exposed. Meticulous sharp and blunt dissection of the synovial cyst was carried out in order to separate it from the dura. The nerve root was identified and the cyst was resected in a piece meal fashion. Decompression of the traversing nerve root was carried out medially and laterally. When the capsule was very adherent to the dura, resection of the cyst content was performed and a thin layer of capsule was left in place in order to prevent a durotomy. The dura and the exiting nerve root were still amenable to decompression. The specimen was sent for pathological confirmation in all cases.

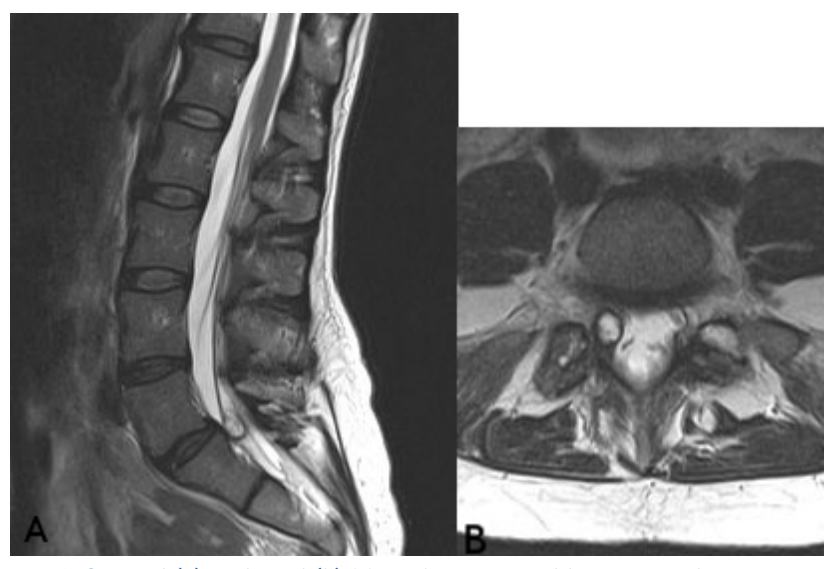

Fig. 1. Sagittal (a) and axial (b) MRI of a 45 year old woman with severe right leg pain caused by an L5-S1 synovial cyst. 
Postoperative radicular pain outcome at follow up and statistical analyses

Radicular pain outcomes were graded using a modification of the Macnab criteria ${ }^{20}$ : excellent, complete resolution of leg pain; good, marked improvement but with occasional mild leg pain; fair, some improvement but with significant functional restrictions and the need of pain medications; and poor, no change in or worsening of leg pain. Radicular pain outcome data were grouped into 2 postoperative time intervals: 1-8 weeks and $>8$ weeks, and were compared between patients with and without spondylolisthesis. The Fisher exact test was used to compare categorical data in 2 groups. The chi-square test was used for comparing more than 2 groups of categorical data. Continuous data were compared with the Student's unpaired $t$-test except for spondylolisthesis measurements that were compared with paired $t$-test. Statistical significance was set at $\mathrm{P}<0.05$.

\section{Results}

\section{Patient Population}

The study included a total of 53 synovial cyst patients. Of these, 18 patients (34\%) presented initially with a grade 1 degenerative spondylolisthesis at the level of the synovial cyst (Table 1). All patients had refractory radicular leg pain at initial presentation. A higher percentage of patients with spondylolisthesis had low back pain $(67 \%$ vs $57 \% ; P=0.565)$ and motor weakness $(28 \%$ vs $9 \% ; P=0.100)$ but these differences did not reach statistical significance (Table 1). There was no statistical difference between the groups with and without spondylolisthesis for the variables gender $(P=1.000)$, age $(P=0.376)$, side $(P$ $=0.780)$, level $(P=0.867)$ and cyst size $(P=0.239)$ (Table 1).

\section{Surgical endpoints and complications}

The presence of spondylolisthesis did not affect the operative time $(P=0.599)$, the amount of blood loss $(P=0.096)$ and the length of hospital stay $(P=0.101)$ (Table 2). There were two complications in the series. One patient in the group without spondylolisthesis had a delayed cerebrospinal fluid (CSF) leak that was not encountered intraoperatively and required reoperation several weeks postoperatively. One patient in the synovial cyst with spondylolisthe- sis group had an intraoperative CSF leak that was repaired at the time of surgery and did not require additional treatment.

\section{Radicular pain outcome}

Radicular pain outcome data between the 1st and 8th postoperative weeks were collected in all 53 patients. During this time period, the mean follow-ups of patients without and with spondylolisthesis did not differ significantly $(30 \pm 3(\mathrm{n}=35)$ vs $34 \pm 4(\mathrm{n}=18)$ postoperative days; $P=0.431$ ). Radicular pain outcome after the 8 th postoperative week were collected in 40 patients and no statistical difference in mean

Table 1. Patients characteristics without and with spondylolisthesis before surgery.

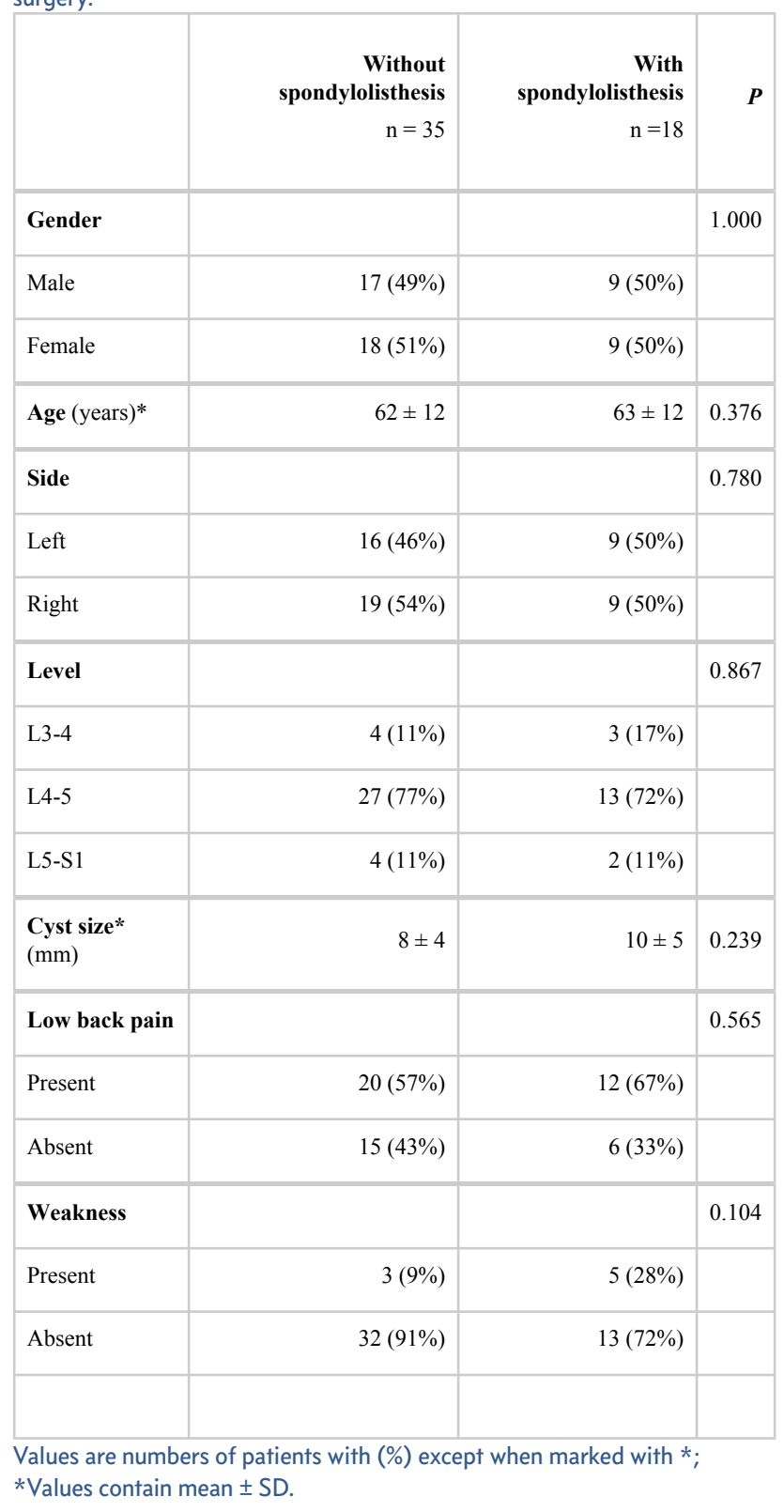


follow-ups was noted between patients without and with spondylolisthesis $(490 \pm 1013(\mathrm{n}=28)$ vs $282 \pm$ $715(\mathrm{n}=12)$ postoperative days; $P=0.281)$.

Between the 1st and 8th postoperative weeks, all 53 patients had either an excellent or a good radicular pain outcome (Table 3) and there was no statistical difference in outcomes between patients without and with spondylolisthesis $(P=1.000)$. After the 8 th postoperative week (mean (SD) follow-up length of 200 (175) weeks), excellent or good outcomes were noted in $89 \%$ of patients without spondylolisthesis and in $75 \%$ of patients with spondylolisthesis (Table 3). The presence of spondylolisthesis did not have a significant effect on the radicular pain outcome after the 8 th postoperative week $(P=0.425)$.

The global outcome of all patients (with and without spondylolisthesis) at the last follow-up visit was excellent or good in $89 \%$ of patients (Table 4 ). The mean last visit follow-up for all 53 patients was 14.8 $(\mathrm{SD}=33.7)$ months.

Development of new spondylolisthesis and spondylolisthesis measurements before and after minimally invasive synovial cyst resection

In the group without spondylolisthesis $(\mathrm{n}=35), 9 \mathrm{pa}-$ tients had a lumbar spine $\mathrm{x}$-ray at follow-up (mean follow-up \pm SD: $2.6 \pm 2.1$ years). The clinical reason for imaging was low back pain. In 4 of these patients (44\%), a new grade 1 spondylolisthesis was found at the level operated (mean measurement \pm SD: $5 \pm 1$ $\mathrm{mm})$. Spondylolisthesis in one of these patients was diagnosed after a fall from own height. One of these patients presented with refractory mechanical low back pain and radiculopathy and was treated with a lumbar fusion.

Table 2. Surgical endpoints in patients without and with spondylolisthesis.

\begin{tabular}{|l|r|r|r|}
\hline & $\begin{array}{r}\text { Without } \\
\text { spondylolisthesis } \\
\mathrm{n}=35\end{array}$ & $\begin{array}{r}\text { With } \\
\text { spondylolisthesis } \\
\mathrm{n}=18\end{array}$ & $\boldsymbol{P}$ \\
\hline $\begin{array}{l}\text { Operative time } \\
\text { (min) }\end{array}$ & $184 \pm 34$ & $178 \pm 31$ & 0.599 \\
\hline Blood loss (mm) & $40 \pm 11$ & $45 \pm 9$ & 0.096 \\
\hline $\begin{array}{l}\text { Length of stay } \\
\text { (days) }\end{array}$ & $0.17 \pm 0.4$ & $0.5 \pm 1.0$ & 0.101 \\
\hline
\end{tabular}

The mean \pm SD measurement of preoperative spondylolisthesis $(\mathrm{n}=18)$ was $5 \pm 2 \mathrm{~mm}$. In this group, 9 patients $(50 \%)$ had a follow-up lumbar x-ray for low back pain (mean follow-up \pm SD: $1.2 \pm 1.3$ years). There was no statistical difference in spondylolisthesis measurements before surgery and at follow-up ( $5 \pm 0$ vs $5 \pm 1 \mathrm{~mm} ; P=0.791$ ).

Patients that required lumbar fusion or decompression after minimally invasive synovial cyst resection Two patients in the group without spondylolisthesis (6\%) had a lumbar fusion at follow-up. The first patient developed a grade 1 spondylolisthesis with refractory mechanical low back pain and recurrent leg pain 3 years and 6 months after the synovial cyst resection at the same level. He then underwent a L4-5 laminectomy with posterior instrumented fusion. The second patient had a L4-5 laminectomy and fusion with bilateral synovial cysts resection 7 months after a right synovial cyst resection at the same level. One patient had a L4-5 minimally invasive left synovial cyst resection 5 years after a right synovial cyst resection at the same level but did not require a lumbar fusion.

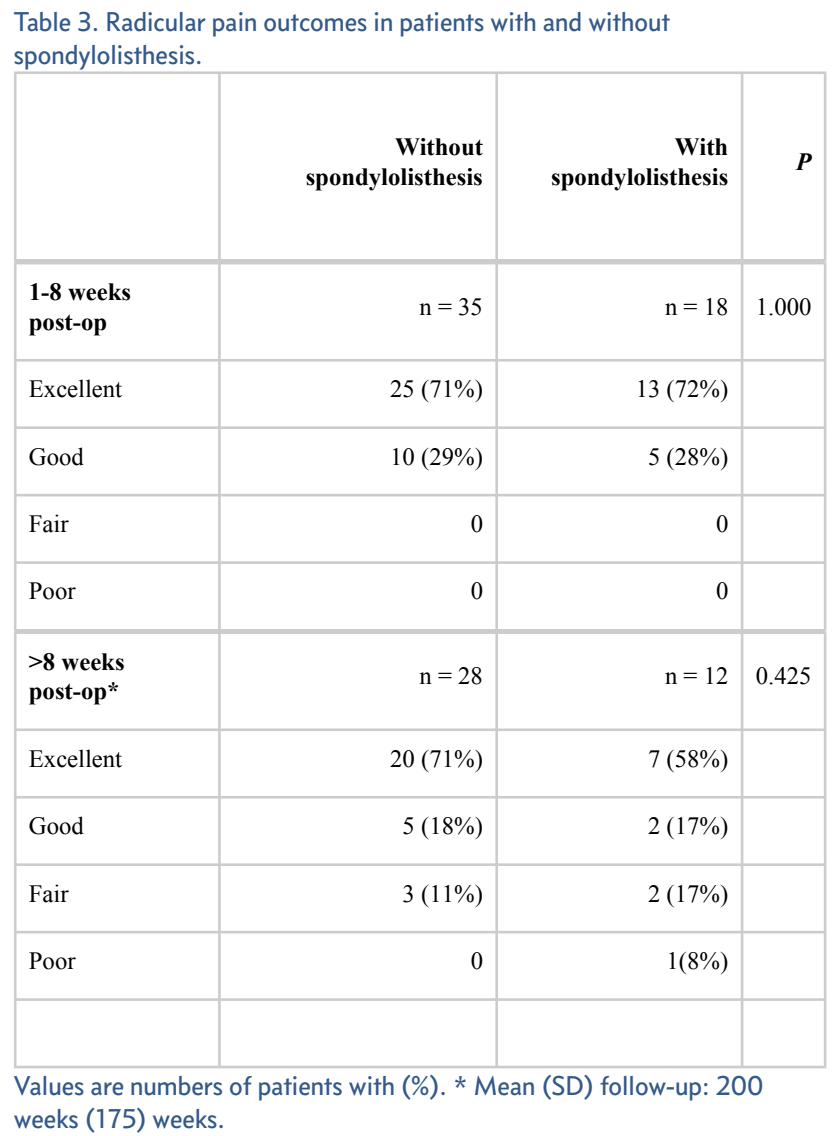


One patient in the spondylolisthesis group had a lumbar fusion at follow-up. This patient had a L4-5 laminectomy and posterior instrumented fusion for refractory low back and radicular pain 1 year and 2 months after a L3-4 synovial cyst resection. Another patient with spondylolisthesis had a L4-5 microdiscectomy 1 year after a synovial cyst resection at the same level.

\section{Discussion}

Lumbar synovial cysts are thought to arise from seg-

Table 4. Review of published case series on minimally invasive resection of synovial cysts through tubular retractor.

\begin{tabular}{|r|r|r|r|r|r|}
\hline & $\begin{array}{r}\text { Present } \\
\text { study }\end{array}$ & $\begin{array}{r}\text { Sandhu } \\
\text { et al, } \\
2004\end{array}$ & $\begin{array}{r}\text { Sehati } \text { et } \\
\text { al, 2006 }\end{array}$ & James et al, & $\begin{array}{r}\text { Sukkarieh } \\
\text { et al, 2015 }\end{array}$ \\
\hline
\end{tabular}

\begin{tabular}{|c|c|c|c|c|c|}
\hline $\begin{array}{l}\text { Patients } \\
\text { characteristics }\end{array}$ & & & & & \\
\hline $\mathrm{n}$ of patients & 53 & 17 & 19 & 16 & 13 \\
\hline Mean age & 63 & 64 & 64 & 67 & 66 \\
\hline $\begin{array}{l}\% \text { of synovial } \\
\text { cyst at L4-5 }\end{array}$ & $75 \%$ & $82 \%$ & $84 \%$ & $56 \%$ & $69 \%$ \\
\hline $\begin{array}{l}\% \text { of Grade } 1 \\
\text { spondylolisthesis }\end{array}$ & $34 \%$ & $47 \%$ & $11 \%$ & $56 \%$ & $31 \%$ \\
\hline \multicolumn{6}{|l|}{ Operative Data } \\
\hline Approach & Ipsilateral & Ipsilateral & Ipsilateral & Contralateral & Contralateral \\
\hline
\end{tabular}

\begin{tabular}{|l|r|r|r|r|r|}
\hline Approach & Ipsilateral & Ipsilateral & Ipsilateral & Contralateral & Contralateral \\
\hline $\begin{array}{l}\text { Operative time } \\
\text { (min) }\end{array}$ & 182 & 97 & 158 & 105 & 123 \\
\hline $\begin{array}{l}\text { Average blood } \\
\text { loss (ml) }\end{array}$ & 41 & 35 & 31 & $<40$ & 44 \\
\hline
\end{tabular}

\begin{tabular}{|l|l|l|l|l|}
\hline $\begin{array}{l}\text { \% patients } \\
\text { discharged }\end{array}$ & $80 \%$ & $82 \%$ & & \\
\hline
\end{tabular}

\begin{tabular}{|l|l|l|l|l|l|}
\hline $\begin{array}{l}\text { discharged } \\
\text { within 24 hours } \\
\text { from surgery }\end{array}$ & $80 \%$ & $82 \%$ & $68 \%$ & $50 \%$ & $>50 \%$ \\
\hline
\end{tabular}

\begin{tabular}{|l|r|r|r|r|r|}
\hline $\begin{array}{l}\text { Mean length of } \\
\text { follow-up } \\
\text { (months) }\end{array}$ & $14.8 \pm$ & $13 \pm 11.0$ & $\begin{array}{l}16 \text { (range } \\
4-29 \text { mo) }\end{array}$ & $14 \pm 9.4$ & $20.8 \pm 16.9$ \\
\hline
\end{tabular}

(months)

Outcome

modified

modified

\begin{tabular}{|l|l|l|l|l|l|}
\hline Excellent & $70 \%$ & $82 \%$ & $53 \%$ & $69 \%$ & $69 \%$ \\
\hline
\end{tabular}

\begin{tabular}{|l|r|r|r|r|r|}
\hline Good & $19 \%$ & $12 \%$ & $42 \%$ & $31 \%$ & $8 \%$ \\
\hline
\end{tabular}

\begin{tabular}{|l|l|l|l|l|l|}
\hline Fair & $9 \%$ & $0 \%$ & $5 \%$ & $0 \%$ & $?{ }^{*}$ \\
\hline Poor & $2 \%$ & $6 \%$ & $0 \%$ & $0 \%$ & $? *$ \\
\hline
\end{tabular}

Complications Intraoperative CSF leak

Postoperative

symptomatic cs

leak

Postoperative

instability

requiring lumba

fusion

Recurrence or new synovial cyst at the same level

* Authors reported patients as having persistent pain without specifying if the pain improved or stayed the same. mental instability, increased abnormal motion and/or trauma. The association between lumbar synovial cysts and degenerative spondylolisthesis, which was found in $34 \%$ of our patients, suggests that both pathologies share a common etiology. ${ }^{11}$ Degenerative spondylolisthesis is thought to result from progressive degeneration of the disc space with concomitant destabilization of the facet complex. ${ }^{21,22}$ In this context, hypermobility and microtraumatic injuries of the facets joint could theoretically induce formation and growth of synovial cyst. Supporting this theory is the fact that both synovial cyst and degenerative spondylolisthesis are most commonly found at the L4-5 level which is the most caudal segment with sagittally oriented facet joints. ${ }^{6,23,24}$ Proportions of synovial cysts located at L4-5 in previously published surgical series range from $56 \%$ to $82 \%{ }^{6,7,15,16,25}$ In our study, synovial cysts of patients without or with spondylolisthesis were located at similar levels, with the L4-5 level being the most common site (77\% and $72 \%$ respectively). The other synovial cysts were distributed almost evenly between L3-4 and L5-S1 (Table 1).

Our groups with and without spondylolisthesis were comparable for all preoperative clinical variables (Table 1). After minimally invasive synovial cyst resection, the radicular pain outcomes in the early and late postoperative periods were not significantly affected by the presence of a grade 1 degenerative spondylolisthesis (Table 3). All patients with or without spondylolisthesis had either an excellent or a good outcome between the 1st and 8th postoperative week. After the 8th post-operative week, a combined excellent/good outcome was shown in $89 \%$ of patients without spondylolisthesis and in $75 \%$ of patients with spondylolisthesis. Several surgical synovial cysts series that contained a significant proportion of patients with concomitant degenerative spondylolisthesis has been published previously (see in Shah and Lutz, 2003). However, to our knowledge, only the study of Epstein (2004) did compare the pain outcomes following synovial cyst resection between patients with or without spondylolisthesis. Epstein (2004) has reported surgeon-based outcome data at 2 years following laminectomy without fusion in 45 patients without spondylolisthesis and in $35 \mathrm{pa}-$ tients with spondylolisthesis. They reported a com- 
bined excellent/good pain outcome in $58 \%$ of patient without spondylolisthesis and in $63 \%$ of patients with spondylolisthesis.

Four other studies on minimally invasive resection of synovial cysts through tubular retractors have been published in the literature (Table 4). The techniques reported in these studies consist of a decompression through either an ipsilateral ${ }^{16,17}$ or a contralateral incision. ${ }^{15,18}$ The Sehati et al. (2006) paper reported the first 19 synovial cysts patients that were operated by the same senior author of the present study. Using the Macnab criteria to assess pain outcome, all minimally invasive studies published so far have shown a combined excellent/good outcome in $77 \%$ to $100 \%$ of patients (Table 4). Patients with grade 1 spondylolisthesis reported in minimally invasive studies are in the range of $11 \%$ to $56 \%$ of patients (Table 4 ). Our study is the first to compare radicular pain outcome between patients with and without spondylolisthesis after minimally invasive resection of synovial cyst.

In this study, we choose to divide the outcome data in 2 postoperative time windows to better depict the effect of time after surgery (Table 3). All patients between the first and 8th postoperative weeks had either an excellent or good pain outcome, meaning that decompression and resection of synovial cyst provided an immediate radicular pain relief. After the 8th postoperative week, pain outcome data were collected in $75 \%$ of the patients operated and the combined excellent/good outcome decreased to $89 \%$. Fair or poor outcome was found in 6 of 40 patients at $>8$ weeks of follow-up and was explained by new or recurrence of synovial cysts in 2 patients, segmental instability in 2 patients and a disc herniation in one patient. There was no recurrence of synovial cyst in patients with spondylolisthesis.

The absence of spondylolisthesis progression on radiologic measurements at an average follow-up of 1.2 \pm 1.3 years in 9 patients demonstrates that minimally invasive resection of synovial cyst can be done without compromising segmental stability in these patients. No significant increase of slip percentage has also been demonstrated with minimally invasive decompression in patients with lumbar stenosis and a grade 1 degenerative spondylolisthesis. ${ }^{26}$ However, increased segmental instability following minimally invasive decompression remains a potential risk as we report 4 out of 9 patients without spondylolisthesis who developed a new grade one spondylolisthesis after a mean follow-up of $2.6 \pm 2.1$ years. James et al. (2012) and Sukkarieh et al. (2015) suggested that a contralateral facet sparing approach is less likely to destabilize the spine than an ipsilateral approach. However randomized control studies comparing contralateral and ipsilateral approaches have not yet been published so far.

The role of lumbar fusion for synovial cyst patients remains unclear. Reviews on the management of synovial cyst suggest that lumbar fusion should be considered in the presence of degenerative spondylolisthesis. ${ }^{9,27}$ The rationale behind this recommendation is that synovial cyst recurrence has never been reported with lumbar fusion ${ }^{13}$ and that laminectomy and fusion could possibly produce a better long-term clinical outcome compared to laminectomy alone for patients with stenosis, synovial cyst and spondylolisthesis. ${ }^{24,27} \mathrm{Xu}$ et al. (2010) have shown that within 2 years after surgery, patients with instrumented fusion have a lower incidence of back pain when compared with patients receiving hemilaminectomy or laminectomy alone. However, the lack of prospective randomized studies on the outcome of fusion in synovial cyst patients precludes definitive conclusions. In addition, the risks of adjacent level disease, pseudoarthrosis and infection that can be associated with lumbar fusion need to be considered. According to our results, the presence of a degenerative spondylolisthesis was not associated with a significantly increase in the risk of synovial cyst recurrence. The only 2 patients in our series that presented with a new or recurring synovial cysts did not have a spondylolisthesis at presentation. Considering that there is a high proportion of synovial cyst patients with spondylolisthesis ( $34 \%$ in this study), that the radicular pain outcome is not affected by the presence of spondylolisthesis after a minimally invasive resection and that the percentage of synovial cyst recurrence is low after decompression $(<5 \%),{ }^{7}$ we do not think that lumbar fusion should be considered as the first line of treatment in patients with synovial cyst and degenerative lumbar spondylolisthesis. It is our opinion that lumbar fusion should be considered when 
there is evidence of significant sagittal motion in preoperative imaging or in the cases which postoperative instability follows decompression. In addition, lumbar fusion can be indicated when minimally invasive synovial cyst resection is followed by synovial cyst recurrence, development or progression of spondylolisthesis and refractory mechanical low back pain and or radiculopathy.

Our study results must be interpreted in light of the following limitations. Due to the retrospective nature of the study, the length of follow-up varied between patients. Pain outcome data were collected in $75 \%$ of the patients after the 8 th post-operative week. The radiological outcome data were collected in postoperative patients who presented with a complaint of low back pain and the true incidence of new spondylolisthesis or progression of spondylolisthesis after minimally invasive resection of synovial cyst could not be exactly determined. Although the follow-up length varied between patients, a mean (SD) followup of 200 (175) weeks in 40 patients has permitted to better assess the long-term radicular pain outcome after minimally invasive resection.

\section{References}

1. Bureau NJ, Kaplan PA, Dussault RG. Lumbar facet joint synovial cyst: percutaneous treatment with steroid injections and distention--clinical and imaging follow-up in 12 patients. Radiology. 2001;221(1):179-85.

2. Pendleton B, Carl B, Pollay M. Spinal extradural benign synovial or ganglion cyst: case report and review of the literature. Neurosurgery.

1983;13(3):322-6.

3. Vossschulte K, Borger G. [Anatomic and functional studies of intervertebral disk hernia]. Langenbecks Arch Klin Chir Ver Dtsch Z Chir. 1950;265(3-4):329-55.

4. Azzam CJ. Midline lumbar ganglion/synovial cyst mimicking an epidural tumor: case report and review of pathogenesis. Neurosurgery.

1988;23(2):232-4.

5. Ganau M, Ennas F, Ambu R, Faa G, Maleci A. Excision of synovial cysts: pathology matters. J Neurosurg Spine. 2013;19(2):266-7.
6. Sabo RA, Tracy PT, Weinger JM. A series of 60 juxtafacet cysts: clinical presentation, the role of spinal instability, and treatment. J Neurosurg. 1996;85(4):560-5.

7. Xu R, Solakoglu C, Maleki Z, McGirt MJ, Gokaslan ZL, Bydon A. Hemorrhagic synovial cyst: the possible role of initial trauma and subsequent microtrauma in its pathogenesis: case report. Neurosurgery. 2011;68(3):E858-65; discussion E65.

8. Allen TL, Tatli Y, Lutz GE. Fluoroscopic percutaneous lumbar zygapophyseal joint cyst rupture: a clinical outcome study. Spine J. 2009;9(5):387-95. 9. Bydon M, Papadimitriou K, Witham T, Wolinsky JP, Sciubba D, Gokaslan Z, et al. Treatment of spinal synovial cysts. World Neurosurg. 2013;79(2):375-80. 10. Martha JF, Swaim B, Wang DA, Kim DH, Hill $\mathrm{J}$, Bode R, et al. Outcome of percutaneous rupture of lumbar synovial cysts: a case series of 101 patients. Spine J. 2009;9(11):899-904.

11. Shah RV, Lutz GE. Lumbar intraspinal synovial cysts: conservative management and review of the world's literature. Spine J. 2003;3(6):479-88.

12. Reust $P$, Wendling $D$, Lagier R, Pageaut $G$, Reverdin A, Jacquet G, et al. Degenerative spondylolisthesis, synovial cyst of the zygapophyseal joints, and sciatic syndrome: report of two cases and review of the literature. Arthritis Rheum.

1988;31(2):288-94.

13. Bydon A, Xu R, Parker SL, McGirt MJ, Bydon M, Gokaslan ZL, et al. Recurrent back and leg pain and cyst reformation after surgical resection of spinal synovial cysts: systematic review of reported postoperative outcomes. Spine J. 2010;10(9):820-6.

14. Saavedra-Pozo FM, Deusdara RA, Benzel EC. Adjacent segment disease perspective and review of the literature. Ochsner J. 2014;14(1):78-83.

15. James A, Laufer I, Parikh K, Nagineni VV, Saleh TO, Hartl R. Lumbar juxtafacet cyst resection: the facet sparing contralateral minimally invasive surgical approach. J Spinal Disord Tech.

2012;25(2):E13-7.

16. Sandhu FA, Santiago P, Fessler RG, Palmer S. Minimally invasive surgical treatment of lumbar synovial cysts. Neurosurgery. 2004;54(1):107-11; discussion 11-2.

17. Sehati N, Khoo LT, Holly LT. Treatment of lumbar synovial cysts using minimally invasive surgi- 
cal techniques. Neurosurg Focus. 2006;20(3):E2.

18. Sukkarieh HG, Hitchon PW, Awe O, Noeller J. Minimally invasive resection of lumbar intraspinal synovial cysts via a contralateral approach: review of 13 cases. J Neurosurg Spine. 2015;23(4):444-50.

19. Armin SS, Holly LT, Khoo LT. Minimally invasive decompression for lumbar stenosis and disc herniation. Neurosurg Focus. 2008;25(2):E11.

20. Macnab I. Negative disc exploration. An analysis of the causes of nerve-root involvement in sixtyeight patients. J Bone Joint Surg Am.

1971;53(5):891-903.

21. Crawford NR, Cagli S, Sonntag VK, Dickman CA. Biomechanics of grade I degenerative lumbar spondylolisthesis. Part 1: in vitro model. J Neurosurg. 2001;94(1 Suppl):45-50.

22. Melnyk AD, Kingwell SP, Zhu Q, Chak JD, Cripton PA, Fisher CG, et al. An in vitro model of degenerative lumbar spondylolisthesis. Spine (Phila Pa 1976). 2013;38(14):E870-7.

23. Anderson DG, Limthongkul W, Sayadipour A, Kepler CK, Harrop JS, Maltenfort M, et al. A radiographic analysis of degenerative spondylolisthesis at the L4-5 level. J Neurosurg Spine. 2012;16(2):130-4. 24. Khan AM, Girardi F. Spinal lumbar synovial cysts. Diagnosis and management challenge. Eur Spine J. 2006;15(8):1176-82.

25. Pirotte B, Gabrovsky N, Massager N, Levivier M, David P, Brotchi J. Synovial cysts of the lumbar spine: surgery-related results and outcome. J Neuro- surg. 2003;99(1 Suppl):14-9.

26. Jang JW, Park JH, Hyun SJ, Rhim SC. Clinical Outcomes and Radiologic Changes Following Microsurgical Bilateral Decompression via a Unilateral Approach in Patients With Lumbar Canal Stenosis and Grade I Degenerative Spondylolisthesis With a Minimum 3-year Follow-up. J Spinal Disord Tech. 2012. 27. Epstein NE. Lumbar laminectomy for the resection of synovial cysts and coexisting lumbar spinal stenosis or degenerative spondylolisthesis: an outcome study. Spine (Phila Pa 1976).

2004;29(9):1049-55; discussion 56.

\section{Disclosures \& COI}

The authors have not received any financial support for this work. There are no conflicts of interest involved in the production of this manuscript.

\section{Corresponding Author}

Daniel Denis, 1514 Jefferson Hwy, New Orleans, LA, 70121.danieldenisjr@gmail.com.

Published 24 October 2016.

This manuscript is generously published free of charge by ISASS, the International Society for the Advancement of Spine Surgery. Copyright $\odot 2016$ ISASS. To see more or order reprints or permissions, see http://ijssurgery.com. 